\title{
Adrenal hemorrhage: A single center experience and literature review
}

\author{
Izabela M. Karwacka ${ }^{A-F}$, Łukasz Obołończyk ${ }^{C-E}$, Krzysztof Sworczak ${ }^{A, C-F}$ \\ Department of Endocrinology and Internal Diseases, Medical University of Gdańsk, Poland \\ A - research concept and design; B - collection and/or assembly of data; $\mathrm{C}$ - data analysis and interpretation; \\ $D$ - writing the article; $E$ - critical revision of the article; $F$ - final approval of the article
}

\author{
Address for correspondence \\ Izabela M. Karwacka \\ E-mail: izabelakarwacka@gmail.com \\ Funding sources \\ None declared \\ Conflict of interest \\ None declared
}

Received on October 27, 2016

Reviewed on November 18, 2016

Accepted on February 9, 2017

\begin{abstract}
Background. Adrenal hemorrhage (AH) is a rare condition that can lead to acute adrenal insufficiency and may be fatal. The risk factors of AH include focal adrenal lesion, abdominal trauma and anticoagulation therapy. The clinical manifestation of AH varies widely; the symptoms may be related to adrenal insufficiency or may reflect multiple organ failure. However, in many cases, the course of AH is asymptomatic.
\end{abstract}

Objectives. The study is a retrospective analysis of 23 cases of $\mathrm{AH}$, whose aim is to discuss the etiology and the management of selected patients, as well as a literature review.

Material and methods. The paper presents a retrospective analysis of 23 patients with AH confirmed by radiological and/or pathological examination. Epidemiological data, the results of laboratory tests, and radiological and pathological examinations were included in the analysis.

Results. The risk factors of AH were not established in 13 patients, 5 patients had experienced a trauma prior to AH diagnosis, 1 patient was diagnosed with sepsis, 2 patients had concomitant neoplastic disease, and in 2 patients, 2 risk factors were present. Among patients who required emergency admission, 5 patients were hospitalized due to acute abdominal pain, 1 patient due to sepsis and 1 patient due to symptoms of active endocrinopathy. In the remaining patients, diagnostic procedures were prompted by the detection of adrenal incidentaloma (Al). A total of $40 \%$ of patients underwent surgical treatment due to the magnitude of AH or clinical and laboratory evidence of overt endocrinopathy. In the remaining patients, conservative treatment and further observation was recommended. In 34.8\% of these patients, follow-up examinations revealed a gradual regression.

Conclusions. It seems that there is a need to distinguish patients with AH who do not require surgical intervention. Follow-up radiological examination is necessary to reassess the lesion. The patients in whom shrinkage of the tumor can be observed are likely not to require surgical treatment.

Key words: adrenal glands, hemorrhage, pseudocyst, primary adrenal insufficiency, adrenal incidentaloma

DOI

10.17219/acem/68897

\section{Copyright}

Copyright by Author(s)

This is an article distributed under the terms of the

Creative Commons Attribution Non-Commercial License

(http://creativecommons.org/licenses/by-nc-nd/4.0/) 


\section{Introduction}

Adrenal hemorrhage $(\mathrm{AH})$ is a rare condition that can lead to acute adrenal insufficiency and may be fatal. It is potentially life-threatening when the adrenal glands are involved bilaterally, although at least $90 \%$ of each adrenal cortex must be compromised before this is clinically evident. The incidence of spontaneous AH based on data from autopsy studies is $0.14-1.1 \%$. The risk factors of AH include focal adrenal lesion, abdominal trauma, anticoagulation therapy, congenital or acquired bleeding disorders, sepsis, and pregnancy., Bleeding of an adrenal gland tumor is most frequently observed in pheochromocytoma and adrenal metastases. ${ }^{1,3-6}$ Larger lesions of adrenal myelolipoma $(>5 \mathrm{~cm})$ rarely present with acute retroperitoneal AH. ${ }^{6}$ The clinical manifestation of AH varies widely; the symptoms may be related to adrenal insufficiency or may reflect multiple organ failure. However, in many cases, the course of $\mathrm{AH}$ is asymptomatic. ${ }^{7}$

Until recently, AH diagnosis was often made at postmortem examination. ${ }^{8}$ Currently, due to the increased availability of modern imaging techniques, $\mathrm{AH}$ is more frequently diagnosed intravitally and in many cases lesions in the adrenal glands are detected unexpectedly (adrenal incidentaloma - AI). The features of $\mathrm{AH}$ on radiological imaging are specific; therefore, its diagnosis based on imaging studies is relatively simple. ${ }^{8,9}$

Data on $\mathrm{AH}$ in the literature are scarce and management standards have not been precisely established. It seems that there is a need to redefine AH risk factors and to establish guidelines for the management of high-risk patients, particularly considering that some AH cases may be associated with metastases or pheochromocytoma.

This paper summarizes data on 23 cases of $\mathrm{AH}$, and discusses the etiology and the management of selected patients.

\section{Material and methods}

This paper presents a retrospective analysis of 23 patients with $\mathrm{AH}$ confirmed by radiological and/or pathological examination. The study group included patients treated at the Department of Endocrinology and Internal Diseases and the Outpatient Clinic of the University Clinical Center in Gdańsk from 2002 to 2016. Epidemiological data, the results of laboratory tests, and radiological and pathological examinations were included in the analysis.

\section{Results}

The study group included 23 patients; $60.8 \%$ women and $39.2 \%$ men. The mean age was 60.6 years (Table 1 ).

The risk factors of $\mathrm{AH}$ were not established in 13 patients (56.6\%), 5 patients $(21.8 \%$ ) had experienced a trauma prior to AH diagnosis, 1 patient (4.3\%) was diagnosed with sepsis, 2 patients $(8.7 \%)$ had concomitant neoplastic disease, and in 2 patients (8.7\%), 2 risk factors were present: anticoagulant drugs and lung cancer, and trauma and chronic oral anticoagulation.

Among patients who required emergency admission, 5 patients $(21.7 \%)$ were hospitalized due to acute abdominal pain, 1 patient (4.3\%) due to sepsis and 1 patient (4.3\%) due to symptoms of active endocrinopathy. In the remaining 16 patients (69.7\%), diagnostic procedures were prompted by AI. The symptoms of adrenal insufficiency (in the course of sepsis) were confirmed in 1 patient, and 1 patient had treatment-resistant hypertension. The rest of the patients were asymptomatic.

The results of biochemical tests and hormone assays in serum and urine - e.g., cortisol, adrenocorticotropic hormone $(\mathrm{ACTH})$, androstenedione, dehydroepiandrosterone sulfate, and metoxycatecholamine (MT) - and radiological images of the study participants were analyzed. In 13 patients $(56.2 \%)$, laboratory test results were within the range of normal values. The remaining 10 patients had laboratory abnormalities, including biochemical markers of adrenal insufficiency (4.3\%), hypercortisolemia (8.7\%), elevated urinary MTs (mainly normetanephrine, 21.8\%), and disorders of both the corticotropic axis and MT secretion (8.7\%). In all patients, computed tomography (CT) examination was performed. A lesion in the right adrenal gland was found in 12 patients (52.2\%), a lesion in the left adrenal gland was found in 10 patients (43.5\%), and 1 patient had bilateral lesions. The diameter of the AH ranged from 17 to $150 \mathrm{~mm}$ (mean diameter: $60.6 \mathrm{~mm}$ ) (Table 2).

Nine patients underwent surgical treatment (40\%) due to the magnitude of $\mathrm{AH}$ or to clinical and laboratory evidence of overt endocrinopathy. The patient in whom both an elevated MT level and hypercortisolemia were found was disqualified from surgery due to the burden of concomitant diseases. It should be stressed that the results of radiological examinations did not raise any oncological concerns. Moreover, pathological assessment unequivocally indicated $\mathrm{AH}$; only in 1 specimen was $\mathrm{AH}$ with the presence of neoplastic cells (a metastasis from lung cancer) found. In the remaining group of patients $(n=14 ; 60 \%)$ conservative treatment and further observation was recommended. In this group, specific risk factors were identified (sepsis, trauma and anticoagulation) and no clinical or laboratory evidence of endocrinopathy was observed, while the adrenal lesions were explicitly described in CT reports as AH. Follow-up examinations performed in 8 patients (34.8\%) revealed a gradual regression of $\mathrm{AH}$, and in the patient with bilateral lesions, a complete absorption of hematomas was found. Table 2 summarizes the clinical course of $\mathrm{AH}$ in the study population.

\section{Discussion}

The pathophysiological mechanism of AH remains unclear. The adrenal glands have unique vasculature providing abundant blood supply, which significantly increases 
Table 1. Study group characteristics

\begin{tabular}{|c|c|c|c|c|c|c|c|c|}
\hline No. & Age & Gender & Risk factor & $\begin{array}{l}\text { Adrenal } \\
\text { gland }\end{array}$ & $\begin{array}{l}\text { Size on CT } \\
{[\mathrm{mm}]}\end{array}$ & Laboratory tests & Intervention & Additional information \\
\hline 1 & 38 & female & trauma & right & $30 \times 17$ & normal & observation & none \\
\hline 2 & 70 & male & $\begin{array}{l}\text { anticoagulant } \\
\text { drugs, lung } \\
\text { cancer }\end{array}$ & right & $55 \times 40$ & elevated normetanephrine & observation & $\begin{array}{c}\text { decreased size of mass to } 25 \mathrm{~mm} \\
\text { at } 18 \text { months }\end{array}$ \\
\hline 3 & 60 & female & urosepsis & bilateral & $52 \times 32$ & adrenal insufficiency & observation & resolution of mass at 12 months \\
\hline 4 & 87 & male & unknown & right & $115 \times 70$ & normal & observation & $\begin{array}{c}\text { decreased size of mass to } 60 \mathrm{~mm} \\
\text { at } 3 \text { months }\end{array}$ \\
\hline 5 & 67 & female & unknown & right & $32 \times 28$ & $\begin{array}{c}\text { hypercortisolemia, elevated } \\
\text { normetanephrine }\end{array}$ & observation & $\begin{array}{c}\text { decreased size of mass to } 25 \mathrm{~mm} \\
\text { at } 12 \text { months }\end{array}$ \\
\hline 6 & 55 & male & unknown & right & $150 \times 10$ & normal & adrenalectomy & histologically hematoma \\
\hline 7 & 73 & female & trauma & right & $85 \times 70$ & normal & adrenalectomy & histologically hematoma \\
\hline 8 & 65 & male & trauma & left & $76 \times 65$ & $\begin{array}{l}\text { hypercortisolemia, elevated } \\
\text { normetanephrine }\end{array}$ & observation & $\begin{array}{c}\text { decreased size of mass to } 75 \mathrm{~mm} \\
\text { at } 2 \text { months }\end{array}$ \\
\hline 9 & 60 & male & unknown & left & $60 \times 60$ & normal & adrenalectomy & histologically hematoma \\
\hline 10 & 51 & female & unknown & right & $64 \times 48$ & normal & adrenalectomy & histologically hematoma \\
\hline 11 & 58 & female & unknown & left & $120 \times 40$ & $\begin{array}{l}\text { hypercortisolemia, elevated } \\
\text { normetanephrine }\end{array}$ & adrenalectomy & histologically hematoma \\
\hline 12 & 62 & female & unknown & right & $62 \times 52$ & normal & adrenalectomy & histologically hematoma \\
\hline 13 & 60 & male & unknown & left & $97 \times 78$ & normal & adrenalectomy & histologically hematoma \\
\hline 14 & 67 & female & unknown & left & $35 \times 25$ & normal & adrenalectomy & histologically hematoma \\
\hline 15 & 53 & female & unknown & left & $43 \times 31$ & hypercortisolemia & adrenalectomy & histologically hematoma \\
\hline 16 & 61 & female & $\begin{array}{l}\text { anticoagulant } \\
\text { drugs, trauma }\end{array}$ & left & $60 \times 60$ & elevated normetanephrine & observation & $\begin{array}{c}\text { decreased size of mass to } 57 \mathrm{~mm} \\
\text { at } 10 \text { months }\end{array}$ \\
\hline 17 & 58 & female & unknown & left & $21 \times 13$ & elevated normetanephrine & observation & $\begin{array}{c}\text { decreased size of mass to } 18 \mathrm{~mm} \\
\text { at } 20 \text { months }\end{array}$ \\
\hline 18 & 64 & male & unknown & right & $1 \times 1$ & elevated normetanephrine & observation & none \\
\hline 19 & 45 & male & trauma & right & $18 \times 9$ & normal & observation & none \\
\hline 20 & 63 & female & unknown & right & $21 \times 15$ & normal & observation & stable size of mass \\
\hline 21 & 60 & female & lung cancer & left & $60 \times 23$ & normal & observation & none \\
\hline 22 & 60 & male & colon cancer & right & $35 \times 25$ & normal & observation & none \\
\hline 23 & 57 & female & trauma & left & $48 \times 33$ & normal & observation & none \\
\hline
\end{tabular}

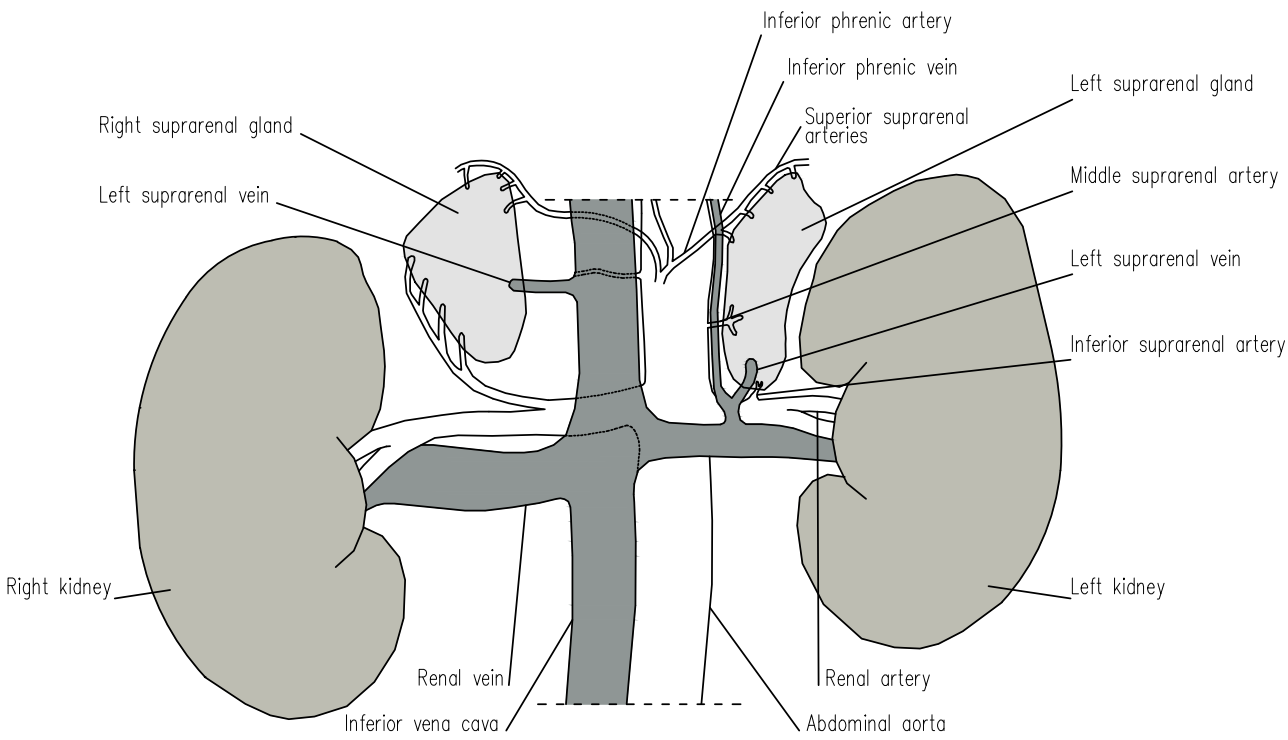

Fig. 1. Anatomical structure and blood supply of the adrenal glands 
Table 2. Study group characteristics

\begin{tabular}{|c|c|c|c|}
\hline Feature & Description & No. & $\%$ \\
\hline Age (mean) & 60.6 years & - & - \\
\hline \multirow{2}{*}{ Gender } & women & 14 & 60.8 \\
\hline & men & 9 & 39.2 \\
\hline \multirow{6}{*}{ Etiology } & trauma & 5 & 21.8 \\
\hline & sepsis & 1 & 4.3 \\
\hline & anticoagulants + neoplasm & 1 & 4.3 \\
\hline & anticoagulants + trauma & 1 & 4.3 \\
\hline & neoplasm & 2 & 8.7 \\
\hline & unknown & 13 & 56.6 \\
\hline \multirow{3}{*}{$\begin{array}{l}\text { Adrenal } \\
\text { gland } \\
\text { involved }\end{array}$} & right adrenal gland & 12 & 52.2 \\
\hline & left adrenal gland & 10 & 43.5 \\
\hline & bilateral & 1 & 4.3 \\
\hline \multirow{4}{*}{$\begin{array}{l}\text { Clinical } \\
\text { presentation }\end{array}$} & acute abdominal pain & 5 & 21.7 \\
\hline & asymptomatic (incidentaloma) & 16 & 69.7 \\
\hline & infection & 1 & 4.3 \\
\hline & evidence of active endocrinopathy & 1 & 4.3 \\
\hline \multirow{5}{*}{$\begin{array}{l}\text { Laboratory } \\
\text { parameters }\end{array}$} & normal & 13 & 56.5 \\
\hline & hypercortisolemia & 2 & 8.7 \\
\hline & elevated metoxycatecholamines & 5 & 21.8 \\
\hline & $\begin{array}{l}\text { hypercortisolemia + elevated } \\
\text { metoxycatecholamines }\end{array}$ & 2 & 8.7 \\
\hline & adrenocortical insufficiency & 1 & 4.3 \\
\hline \multirow{2}{*}{ Intervention } & observation & 14 & 60 \\
\hline & surgical treatment & 9 & 40 \\
\hline
\end{tabular}

the propensity to bleeding. Each adrenal gland is supplied by 3 suprarenal arteries (the superior suprarenal artery, a branch of the inferior phrenic artery; the middle suprarenal artery, a direct branch of the abdominal aorta; and the inferior suprarenal artery, a branch of the renal artery). ${ }^{3,8}$ It should be noted that venous outflow is provided by only 1 suprarenal vein tributary to the inferior vena cava. ${ }^{10}$ Furthermore, it has been suggested that increased capillary resistance may be a significant factor predisposing an individual to AH. Elevated ACTH and MT levels, through their vasoconstrictive effect and excessive platelet activation, may lead to reperfusion and subsequent bleeding, mainly from distal capillary vessels (Fig. 1). ${ }^{6,11}$

Adrenal hemorrhages can be divided into primary (spontaneous or idiopathic) and secondary AHs (of known etiology, e.g., caused by trauma, sepsis or anticoagulation therapy). ${ }^{1}$ The risk factors of AH are summarized in Table 3.

Based on a 25-year observation, Vella et al. divided a group of 141 patients with AH into 7 categories:

1. AH detected as AI - 28 cases;

2. spontaneous $\mathrm{AH}$ manifesting as acute hemorrhage to the abdominal cavity - 16 cases;

3. AH with concomitant hematological disease (antiphospholipid syndrome, systemic lupus erythematosus) - 20 cases;
Table 3. Risk factors of adrenal hemorrhage

\begin{tabular}{|c|c|}
\hline $\begin{array}{c}\text { Conditions predisposing } \\
\text { to } \mathrm{AH}\end{array}$ & Examples \\
\hline Trauma ( $80 \%$ of cases) & - \\
\hline Stress & $\begin{array}{l}\text { - } \text { burns } \\
\text { - hypotension } \\
\text { - } \text { surgery (particularly } \\
\text { orthopedic surgery) }\end{array}$ \\
\hline Infectious disease & $\begin{array}{l}\text { - sepsis caused by Neisseria meningitidis, } \\
\text { Pseudomonas aeruginosa, Escherichia } \\
\text { coli, Bacteroides fragilis, Streptococcus } \\
\text { pneumoniae }\end{array}$ \\
\hline Medication & $\begin{array}{l}\text { - } \text { anticoagulants } \\
\text { - } \text { antiplatelets } \\
\text { - } \text { nonsteroidal anti-inflammatory drugs } \\
\text { - } \text { glucocorticosteroids }\end{array}$ \\
\hline Hematologic disorders & $\begin{array}{l}\text { - } \text { antiphospholipid syndrome } \\
\text { - } \text { systemic lupus erythematosus } \\
\text { - } \text { heparin-induced thrombocytopenia } \\
\text { - } \text { thrombocytosis }\end{array}$ \\
\hline Obstetric causes & $\begin{array}{l}\text { - pregnancy } \\
\text { - postpartum period } \\
\text { - pre-eclampsia }\end{array}$ \\
\hline Perinatal injury & $\begin{array}{l}\text { - } \text { asphyxia } \\
\text { - } \text { perinatal hypoxia } \\
\text { - } \text { sepsis } \\
\text { - fetal hematologic disorders }\end{array}$ \\
\hline Adrenal gland tumor & $\begin{array}{l}\text { - primary: pheochromocytoma, } \\
\text { adrenocortical cancer, myelolipoma, } \\
\text { lipoma, hematoma, angioma, adenoma, } \\
\text { pseudocyst } \\
\text { - metastatic: lung cancer, renal cancer, } \\
\text { breast cancer, colon cancer, thyroid } \\
\text { cancer, gallbladder cancer, melanoma }\end{array}$ \\
\hline Gastrointestinal diseases & - acute pancreatitis \\
\hline
\end{tabular}

$\mathrm{AH}$ - adrenal hemorrhage; ACTH - adrenocorticotropic hormone.

4. postoperative AH (patients who underwent laparoscopic procedures or laparotomy, alloplastic joint replacement and prostatectomy) - 14 cases;

5. AH in patients treated with anticoagulants -3 cases;

6. post-traumatic $\mathrm{AH}-4$ cases;

7. $\mathrm{AH}$ as a complication of sepsis and/or stress -56 cases. $^{8}$

The cases analyzed in our study were mainly AIs with non-established etiology (70\% of patients), which were categorized as group 1 according to Vella's classification. The remaining patients were classified as group 2 or 7 .

The clinical presentation reflects both the intensity of bleeding and the extent of adrenal gland injury. ${ }^{1,9}$ The clinical course in bilateral massive hemorrhage to the adrenal glands is usually dramatic and, if recognized too late, may be fatal. ${ }^{12}$ The patients in whom $\mathrm{AH}$ has been incidentally diagnosed usually do not develop a typical form of $\mathrm{AH}$ and the course of the disease may be asymptomatic. ${ }^{8,13-16}$ In the analyzed group, $91.4 \%$ of cases were asymptomatic; only in 1 patient was clinically overt adrenal insufficiency observed. 

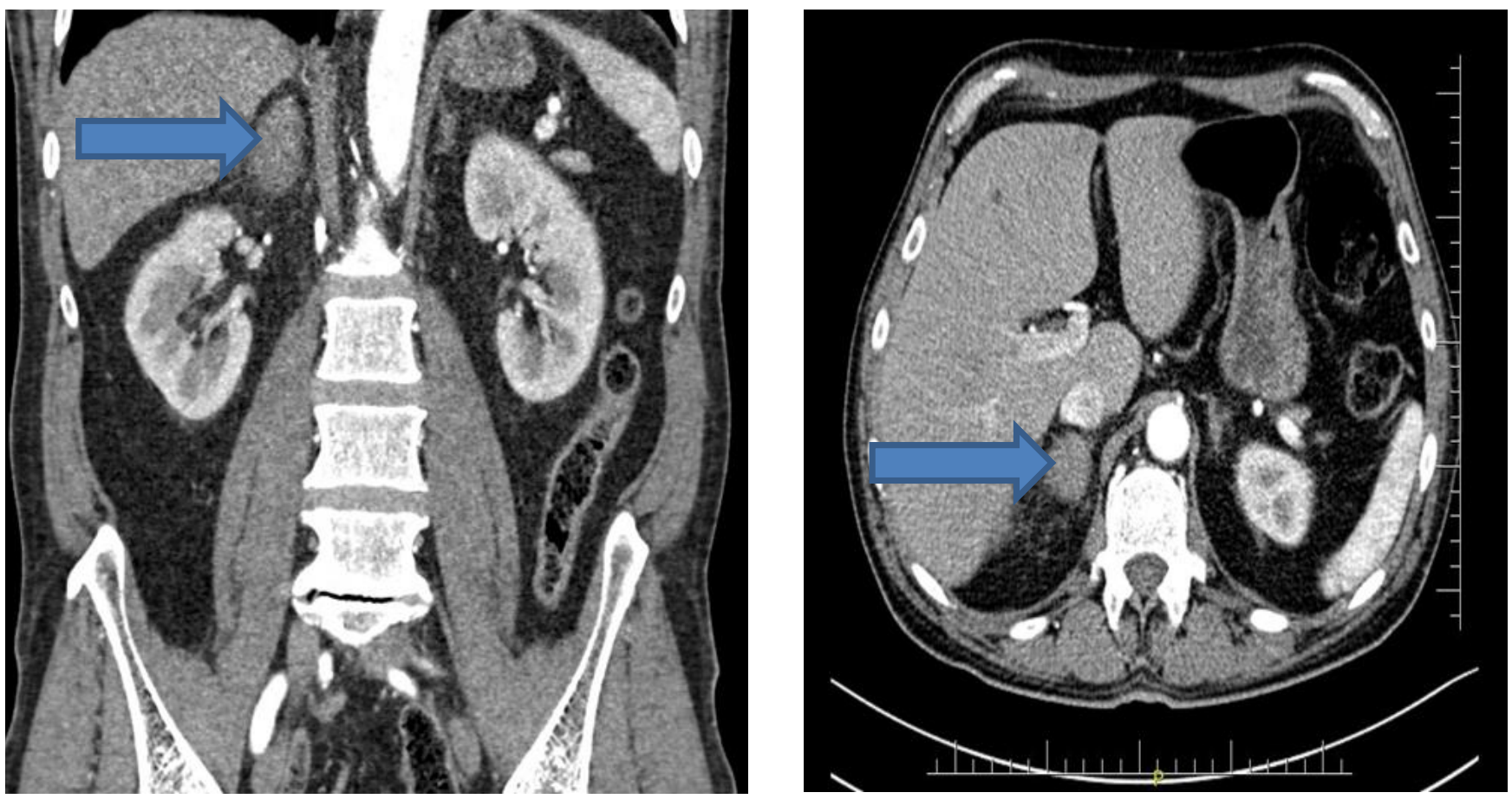

Fig. 2. Patient No. 22: right adrenal hematoma, $35 \mathrm{~mm}$ in diameter (arterial phase CT scan)

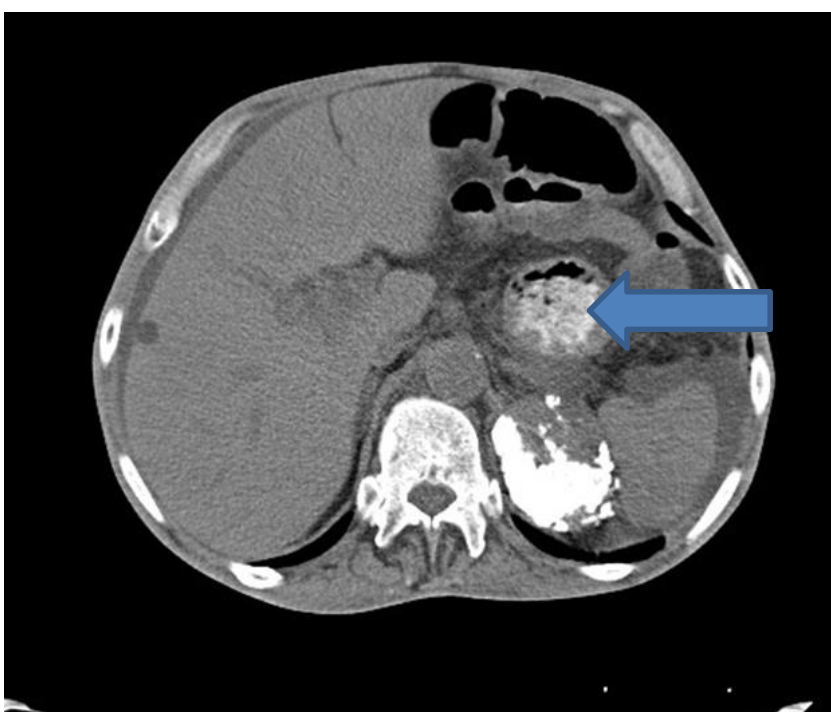

Fig. 3. Patient No. 8: left adrenal hematoma, $70 \mathrm{~mm}$ in diameter, with calcifications (arterial phase CT scan)

Abnormalities of laboratory parameters in patients with $\mathrm{AH}$, such as hyponatremia, hyperkaliemia, hypercalcemia, and hypoglycemia, are biochemical markers of adrenal insufficiency. Anemia is observed in patients with massive bleeding. Thrombocytopenia and bleeding disorders occur in patients with antiphospholipid syndrome or lupus erythematosus. ${ }^{8,17}$ Considering the risk of $\mathrm{AH}$ related to pheochromocytoma and adrenocortical cancer, in patients with these pathologies, the urine MT level measurement and the corticotropic axis assessment should be done. ${ }^{1,18,19}$ In the study group, symptomatic adrenocortical

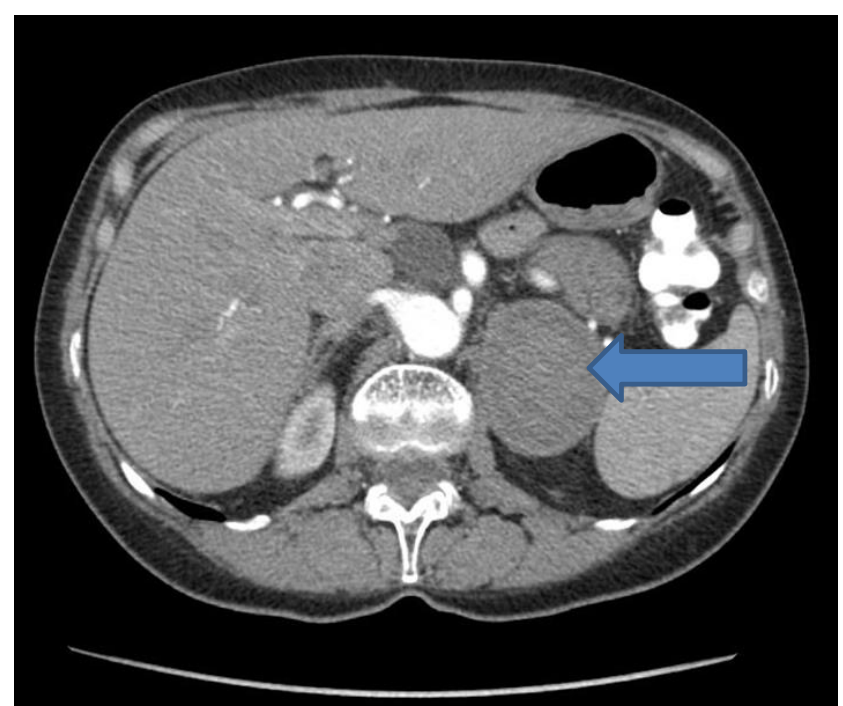

Fig. 4. Patient No. 16: left adrenal hematoma, $60 \mathrm{~mm}$ in diameter (arterial phase CT scan)

insufficiency (in the patient with bilateral AH in the course of sepsis), increased secretion of MT and corticotropic axis disorders were found. Isolated hypersecretion of MT was observed in 5 patients, which could indicate an active neoplastic process (pheochromocytoma is the lesion where AH occurs most frequently); ${ }^{4,5}$ however, MT levels only slightly exceeded normal laboratory range (50-100\% above the upper limit of normal) and the patients did not present symptoms indicative of an excess of catecholamines. For this reason, the above abnormality was considered non-specific and could not be the basis for diagnosing 
pheochromocytoma. Follow-up examination confirmed the spontaneous normalization of MT levels. It should be noted that $56.5 \%$ of patients had normal laboratory values. Similarly, in a group of 6 patients with AH described by Marti et al., 4 patients had normal laboratory test results. ${ }^{1}$

Undoubtedly, the increased availability of imaging examinations resulted in higher rates of $\mathrm{AH}$ diagnosis. The radiological image of $\mathrm{AH}$ depends on the patient's age and the duration and intensity of bleeding. ${ }^{3,20}$ Despite the fact that ultrasonographic (USG) examination is a fast, inexpensive and widely available technique, its use in the diagnosis and monitoring of $\mathrm{AH}$ patients is limited to newborns and infants. $^{3}$ It has been reported that contrast-enhanced ultrasonography (CEUS) can also be used for the diagnosis of adrenal gland tumors, which might enhance the role of this technique in the detection of $\mathrm{AH} .^{21,22}$ The method of choice for critically ill patients is CT scanning, because it allows preliminary differentiation of adrenal hemorrhagic tumors from malignant lesions (10\% of pheochromocytomas, adrenocortical carcinoma and metastases). ${ }^{23,24}$ On CT images, $\mathrm{AH}$ appears as a focal heterogeneous high-density (50-70 Hounsfield units) lesion (Fig. 2). ${ }^{1,25,26}$ With the aging of the hematoma, its gradual shrinkage and even complete regression can be observed. Chronic AH can be seen as an adrenal mass with a hypodense center without calcification, known as an adrenal pseudocyst, and after a year, calcification is often found (Fig. 3). The lack of contrast enhancement allows the hemorrhagic nature of the lesion to be confirmed. ${ }^{3}$ Moreover, Tan et al. presented 4 cases of non-traumatic $\mathrm{AH}$ which demonstrated features of prior adrenal congestion (adrenal gland thickening and periadrenal fat stranding) on CT scans (Fig. 4). ${ }^{27}$ In some cases, magnetic resonance imaging (MRI) can be employed, which is particularly useful for differentiating acute bleeding from chronic bleeding. ${ }^{22,25,26}$ The appearance of hemorrhage on MRI scans depends on the age of hemorrhage, with the signal intensity changing in relation to the progressive degradation of hemoglobin. In the acute phase ( $<2$ days), hemorrhage is hypointense on T1-weighted images and hypointense on a T2 signal (Fig. 5). In the early subacute phase (2-7 days), $\mathrm{AH}$ is seen as a hyperintense $\mathrm{T} 1$ signal and a hypointense T2 signal. A chronic hematoma demonstrates peripheral low $\mathrm{T} 1$ and $\mathrm{T} 2$ signals due to intracellular hemosiderin, with central $\mathrm{T} 2$ hyperintensity and $\mathrm{T} 1$ isointensity. ${ }^{28}$

The management of patients with AH depends on their general health status. Hemodynamically unstable patients require intensive medical treatment for shock and adrenal insufficiency as well as qualification for surgical treatment. Surgery should be also considered in patients with the suspicion of pheochromocytoma and adrenocortical carcinoma, particularly if the size of the tumor in the adrenal gland exceeds $6 \mathrm{~cm} \cdot{ }^{1,19,29}$ Conservative treatment should be considered in patients with bilateral $\mathrm{AH}$, in patients whose $\mathrm{AH}$ was detected as $\mathrm{AI}$, and in those with known

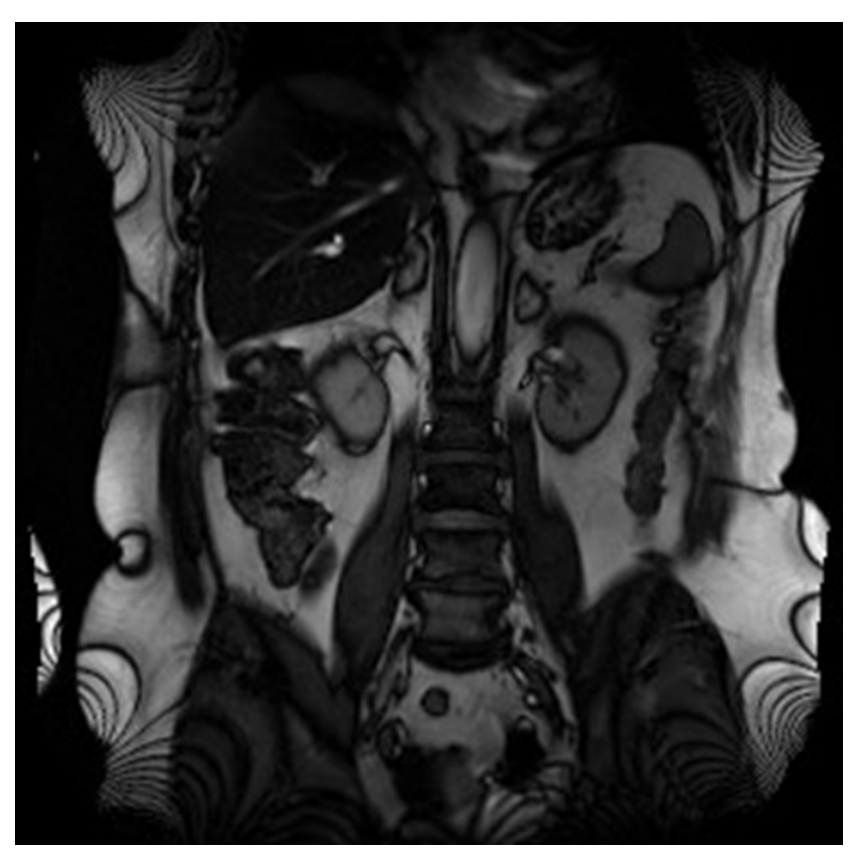

Fig. 5. Patient No. 3: bilateral adrenal hemorrhage; the lesions are $50 \mathrm{~mm}$ in diameter (MRI)

and reversible risk factors (e.g., AH caused by an overdose of anticoagulants). ${ }^{5,30}$ Marti et al. described 6 cases of AH. In the group, 4 patients underwent surgical treatment, whereas the rest of the patients were re-examined. ${ }^{1}$ One patient receiving conservative treatment was on anticoagulation therapy and, burdened with lung cancer metastasizing to the adrenal gland and adrenal hematoma, was qualified for chemotherapy. During the 6-month follow-up examination, a marked regression of the adrenal lesion was found. In another patient who had a history of septic shock complicated with neutropenia and colon perforation, and whose CT scan showed a hematoma with a pseudocyst, a complete regression of the adrenal lesion was observed at the 6-month follow-up visit. Bharucha et al. described bilateral AH with subclinical course in a patient on warfarin therapy in whom conservative treatment proved to be successful. ${ }^{9}$ There are reports on cases of spontaneous bilateral AH manifesting with acute abdominal pain, in which the introduction of hydrocortisone replacement therapy and the withholding of surgical treatment resulted in a significant regression of the lesion confirmed by follow-up imaging. ${ }^{11,24}$

Among the patients included in the analysis, 9 (40\%) underwent surgical treatment, and the decision was made based on the tumor size and the suspicion of active endocrinopathy. The remaining 14 patients $(60 \%)$ were only examined again at follow-up. The factors that determined the choice of conservative treatment were known AH risk factors, an absence of clinical and laboratory markers of endocrinopathy, and a description of the adrenal lesion in the CT report, which unequivocally indicated AH. In $34.8 \%$ of these patients, follow-up imaging examinations showed a partial or total regression of the lesion. 
Therefore, it seems that there is a need to distinguish patients with $\mathrm{AH}$ who do not require surgical treatment, because the natural course of AH may result in spontaneous hematoma resorption and recovery. Follow-up radiological examination is necessary in order to reassess the lesion. The patients in whom shrinkage of the tumor can be observed are likely not to require surgical treatment.

\section{References}

1. Marti JL, Millet J, Sosa JA, Roman SA, Carling T, Udelsman R. Spontaneous adrenal hemorrhage with associated masses: Etiology and management in 6 cases and a review of 133 reported cases. World J Surg. 2012;36:75-82.

2. Simon DR, Pales M. Clinical update on the management of adrenal hemorrhage. Curr Urol Rep. 2009;10:78-83.

3. Kawashima A, Sandler CM, Ernst RD, et al. Imagining of nontraumatic hemorrhage of the adrenal gland. Radiographics. 1999;19:949-963.

4. Jacobs LM, Williams LF, Hinrichs HR. Hemorrhage into a pheochromocytoma. JAMA. 1978;239(12):1156.

5. Nicholls K. Massive adrenal haemorrhage complicating adrenal neoplasm. Med J Aust. 1979;2:560-562.

6. Kumar S, Jayant K, Prasad S, et al. Rare adrenal gland emergencies: A case series of giant myelolipoma presenting with massive hemorrhage and abscess. Nephrourol Mon. 2015;7(1):e22671.

7. Kerkhofs TM, Haak HR, Roumen RM, Demeyere TB, van der Linden AN. Adrenal tumors with unexpected outcome: A review of the literature. Int J Endocrinol. 2015;2015:710514.

8. Vella A, Nippoldt TB, Morris JC III. Adrenal hemorrhage: A 25-year experience at the Mayo Clinic. Mayo Clin Proc. 2001;76:161-168.

9. Bharucha T, Broderick C, Easom N, Roberts C, Moore D. Bilateral adrenal haemorrhage presenting as epigastric and back pain. JRSM Short Rep. 2012;3:15.

10. Milewicz A. Endokrynologia kliniczna. Wrocław: Polskie Towarzystwo Endokrynologiczne; 2011:364-366.

11. Dhawan N, Bodukam VK, Thakur K, Singh A, Jenkins D, Bahl J. Idiopathic bilateral adrenal hemorrhage in a 63-year-old male: A case report and review of the literature. Case Rep Urol. 2015;2015:503638,1-4.

12. Moore MA, Biggs PJ. Unilateral adrenal hemorrhage: An unusual presentation. South Med J. 1985;78:989-992.

13. Christoforides C, Petrou A, Loizou M. Idiopathic unilateral adrenal haemorrhage and adrenal mass: A case report and review of the literature. Hindawi Pub Corp. http://dx.doi.org/10.1155/2013/567186. Accessed March 27, 2013.

14. Hoeffel C, Legmann P, Luton JP, Chapuis Y, Bonnin A. Spontaneous unilateral adrenal hematomas: 10 cases. Presse Med. 1994;23:1023-1026.

15. Bednarczuk T, Bolanowski M, Sworczak K, et al. Adrenal incidentaloma in adults: Management recommendations by the Polish Society of Endocrinology. Endokrynol Pol. 2016;67:234-258.

16. Babińska A, Siekierska-Hellmann M, Błaut K, et al. Hormonal activity in clinically silent adrenal incidentalomas. Arch Med Sci. 2012;8:97-103.

17. Potter EL, Barnes SL, Chunilal SD. Acute adrenal failure due to bilateral adrenal haemorrhage associated with lupus anticoagulant antibodies. Intern Med J. 2015;45:119-120.

18. Trauffer PM, Malee MP. Adrenal pseudocyst in pregnancy: A case report. J Reprod Med. 1996;41:195-197.

19. Dworakowska D, Drabarek A, Wenzel I, Babińska A, ŚwiątkowskaStodulska R, Sworczak K. Adrenocortical cancer (ACC): Literature overview and own experience. Endokrynol Pol. 2014;65:492-502.

20. Dunnick NR. Adrenal imaging: Current status. AJR Am J Roentgenol. 1990;154:927-936.

21. Cantisani V, Petramala L, Ricci P, et al. A giant hemorragic adrenal pseudocyst: Contrast-enhanced examination (CEUS) and computed tomography (CT) features. Eur Rev Med Pharmacol Sci. 2013;17:2546-2550.

22. Friedrich-Rust M, Schneider G, Bohle RM, et al. Contrast-enhanced sonography of adrenal masses: Differentiation of adenomas and nonadenomatous lesions. Am J Roentgenol. 2008;191:1852-1860.

23. Rao RH, Vagnucci AH, Amico JA. Bilateral massive adrenal hemorrhage: Early recognition and treatment. Ann Intern Med. 1989;110:227-235.
24. Wolverson MK, Kannegiesser H. CT of bilateral adrenal hemorrhage with acute adrenal insufficiency in the adult. AJR Am J Roentgenol. 1984;142:311-314.

25. Hiroi N, Yanagisawa R, Yoshida-Hiroi M, et al. Retroperitoneal hemorrhage due to bilateral adrenal metastases from lung adenocarcinoma. J Endocrinol Invest. 2006;29:551-554.

26. Goldman HB, Howard RC, Patterson AL. Spontaneous retroperitoneal hemorrhage from a giant adrenal myelolipoma. J Urol. 1996;155:639.

27. Tan GX, Sutherland T. Adrenal congestion preceding adrenal hemorrhage on CT imaging: A case series. Abdom Radiol. 2016;41:303-310.

28. Hammond NA, Lostumbo A, Adam SZ, et al. Imaging of adrenal and renal hemorrhage. Abdom Imaging. 2015;40:2747-2760.

29. Kashiwagi S, Amano R, Onoda N, et al. Nonfunctional adrenocortical carcinoma initially presenting as retroperitoneal hemorrhage. BMC Surg. 2015;15:46.

30. Kasperlik-Zauska AA, Rosłonowska E, Słowinska-Srzednicka J, et al. Incidentally discovered adrenal mass (incidentaloma): Investigation and management of 208 patients. Clin Endocrinol (Oxf). 1997;46:29-37. 